\title{
Implementation of Almajiri Education Program: The Role of International Development Partners and Civil Society Organizations in Nigeria
}

\author{
Muhammad Alkali PhD \\ Department of Adult Education and Extension Services. \\ Usmanu Danfodiyo University Sokoto, Nigeria
}

\begin{abstract}
This paper observes the roles of development partners and civil societies in the implementation of Almajiri (out of formal school children found on the street begging) Education, Access to quality of basic education is very poor, leading to low demand and unacceptably low academic performance in facts that's why some development partners endeavor to supports Almajiri child formal out of school children in Nigeria by creating much access to quality basic education to formal and non-formal education. About 13.5 million are not enrolled in formally recognized schools. Accordingly, four notable development partners and two civil society organization were identified and the numerous support they offered in Nigeria.
\end{abstract}

Keywords: Implementation, Almajiri, Development Partners, Civil Societies.

DOI: $10.7176 / \mathrm{JEP} / 10-2-10$

\section{Introduction}

Education is a human right that should be accorded to all human beings solely by reason of being human. There are a lot of international human rights instruments that provide for education as a fundamental human right. These include the Universal Declaration of Human Rights (1948), the International Covenant on Economic, Social and Cultural Rights (1966) and the African Charter on Human and Peoples' Rights (1981). The relationship between education and development is well established such that education is a key index of development. It has been documented that schooling improves productivity, health and reduces negative features of life such as child labour as well as bringing about empowerment. This is why there has been a lot of emphasis particularly in recent times for all citizens of the world to have access to basic education.

It is in realization of that Government and Development partners strived and are committed to providing access to education. Despite various efforts to fill in the gap in education it seems a lot need to be done. For instance, according to the EFA Monitoring Team report, an estimated 71 million children of primary school age do not have access to education globally. Nigeria alone in 2018 reported by the Federal Ministry of Education, Abuja to have 13.5 million out-of-school children, emerging in 2012 - 3.6 million more than in 2000 , or 42 percent of the primary school-age population. 17.21 percent of out-of-school children in the world are Nigeria in recent past. It is out of that 13.5 million of out of School children in Nigeria, over 9.5 million are Almajirai mostly in the Northern region of the country. Almajirai are individuals on spiritual and moral values in Qur'anic/Tsangaya centers across the North region of the country. In the Qur"anic Traditional way of teaching and learning where Almajiri child is enrolled, the duration of scholarship as an Almajiri also depend on the on the intellectual capacity capability of the pupil, who is expected to memorised the Qur'an, which he does in 3 stages-learning the Qur'an by heart (tilawa); memorising it (tahafiz), and perfecting his ability to write the whole Qur'an devoid of error on sheet of paper. This usually takes at least a period of 20 or more years to fully accomplish that level task. On this aspect if a child start this studies at the age of six, by the time he sort of graduate he is too old to enroll into conventional or formal schooling. This write up mainly concentrated in few Northern state of Nigeria more particularly Sokoto and Bauchi States where USAID invested more in Education in recent time.

The other aspect of the Almajirci meaning practicing Almajirci (child street begging ) are the short term or seasonal migrant Almajiri's who normally leave home during the dry session (when food stuff most have finished) and stage to start Qur'anic learning and return back home during rainfall session. These generality of children would hardly fit into normal and age-graded conventional system of education. Non-formal Education will perfectly dish up because of its robust and flexibility. Almajiri Education interventions is an enrolment drive free, what we may require is sensitize the affected community for integration and modeling.

Almajiri Education Program: The Role of Development Partners and Civil Societies.

For the purpose of this paper the following development partners and civil societies will be focused on, these organization have a records/elements of working in Almajiri/Qur'ani Integrated Education in Nigeria:

- United Nation International Children Education Funds (UNICEF)

- Education Sector Support Project in Nigeria (ESSPIN) 
- Northern Education Initiative (NEI/USAID funded project)

- Northern Education Initiative plus (NEI-plus/USAID funded Project) While Civil Society will discuss

- Federation of Muslim Women Association of Nigeria (FOMWAN)

- Civil Society Action Coalition on Education for All (CSACEFA)

\section{United Nation International Children Education Funds (UNICEF)}

Nigeria was one of the very first African countries where the United Nations Children's Fund (UNICEF) established a programme of cooperation. UNICEF's work for the survival, protection and development of Nigerian children has continued ever since. Today UNICEF is still working in partnership with many stakeholders including children and families to achieve national and international goals instrumental in the fulfilment of children's rights.

UNICEF is deeply committed to creating a world in which all children, regardless of their gender, socioeconomic background or circumstances, have access to free, compulsory and quality education. UNICEF's mandate to serve the most marginalized populations prompts it to focus special attention on girls, the largest group excluded from education.

\section{UNICEF Innovation to Access to Education}

UNICEF's agenda fits into many international goals related to girls' education, including Millennium Development Goals 2 and 3, to ensure that all children have access to and complete a full course of primary schooling, and to eliminate gender disparity in education by 2015. Other global goals echoing these commitments include the World Education Forum's Dakar platform, which stresses the rights of girls, ethnic minorities and children in difficult circumstances; and A World Fit for Children's emphasis on ensuring girls' equal access to and achievement in basic education of good quality.

In 1995 Sokoto state government and UNICEF agreed to model core academic subjects be integrated into traditional Qur'anic school (makarantar allo) 3 centers were pilot tested and continue to expand and now Sokoto State Agency for Mass Education in partnership with UNICEF managing 313 IQE centers.

They also supported the training of Qur'anic school proprietors for the development of system and influence budgetary provision through the Education Sector Strategic and Operational Plans (ESSOPs). These included situation analysis, scenarios building, projection of school needs, costing of school services,

\section{Education Sector Support Project in Nigeria (ESSPIN)}

ESSPIN is one of a set of DFID-funded State Level Programmes (SLPs), working in governance, accountability and the delivery of health and education services. DFID-ESSPIN supports federal and state authorities as they work both to reform the governance of education and to improve the quality of education that children receive ESSPIN is a partnership between the Nigerian Government and the United Kingdom Department for International Development (DFID). The six-year programme (2008 - 2014) supports federal and state governments -Enugu, Jigawa, Kaduna, Kano, Kwara and Lagos - to develop effective planning, financing and delivery systems that will improve the quality of basic education.

By 2014, ESSPIN will have had a significant impact on 7,500 public and 1,600 non-government schools and approximately 4 million learners. 


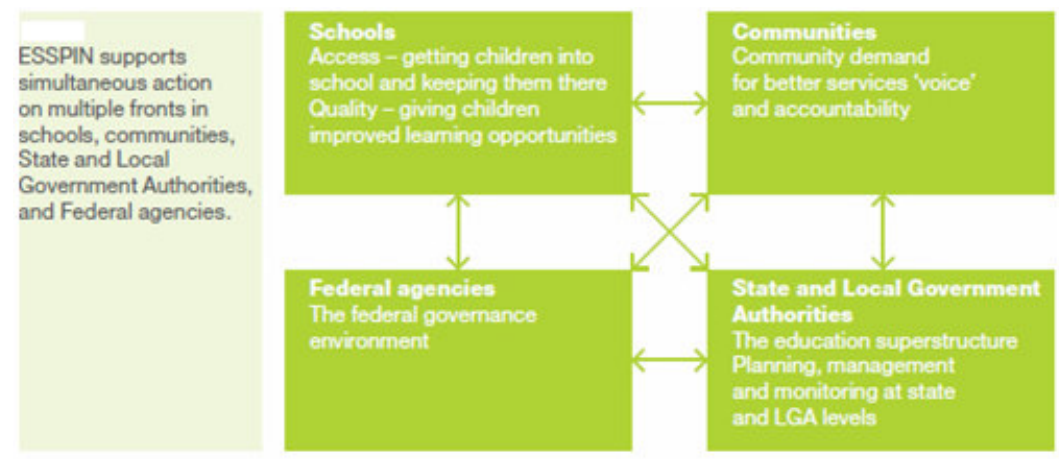

links In Kano, ESSPIN realized that four players have been important in designing of the IQTE strategy and they all need to be on board to develop the implementation plan. These are: Ministry of Education, SUBEB, Sariah Commission and the Office of the Special Advisor to the Governor on IT and Islamic Education. During the visit indiviual meetings were held with representatives from all the four bodies, which were organized by the ESSPIN Kano office. Within SUBEB the main meeting was with the Director of state schools, and within Ministry of Education discussion was held with the Permanent Secretary himself. Within the Shariah Commission, the Commissioner himself asked to join the meeting, which was also attended by directors of all the departments. During these meetings, the actors were reminded of the key strategies proposed within the IQTE strategy plan, namely:

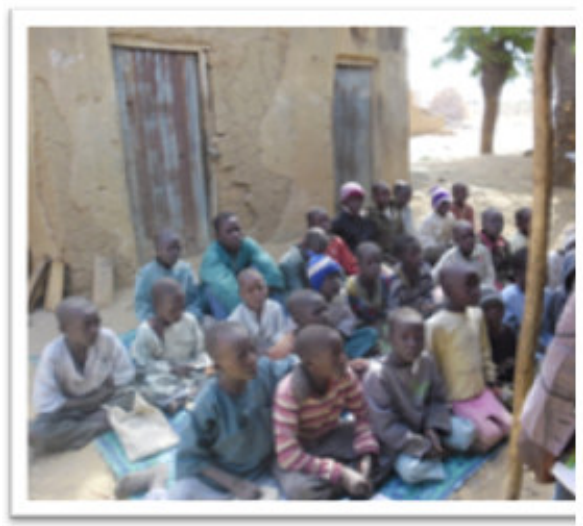

One of the IQTE center in Kano Almajiri class in session

- Provide support for teaching of secular subjects within IQTE schools

- Trial a model of introducing an integrated curriculum within the regular state schools

- Establish an independent Islamic Schools Board

\section{Northern Education Initiative (NEI/USAID)}

NEI is USAID/Nigeria's flagship Education project being implemented in the focus States of Bauchi and Sokoto. Despite the Government of Nigeria's (GON's) commitment to providing universal basic education, the delivery of education services is inadequate, and even more so in northern Nigeria. NEI strengthens state and local government systems that lay the foundation for delivering quality education services for out-of-school youth and orphans and vulnerable children.

In addition, the gender disparities in education between the northern and southern geopolitical zones are stark.

Nationally, about $43 \%$ of primary school-aged girls do not have access to basic education, and approximately two million more girls than boys are out of school. In northern Nigeria, the percentage of girls who have ever attended school stands at $34 \%$ and $39 \%$, respectively; for secondary school the figures are $10 \%$ and $15 \%$.

\section{NEI Strategy:}

NEI strengthens state and local government capacity to deliver basic education services by addressing key management, sustainability, and oversight issues at the basic education level in selected northern Nigerian states. 
Strengthened systems include policy development and implementation; information management and data for decision-making; and human resource development and management, including training, monitoring, and supervision.

\section{Increased access to basic education and other services}

NEI works to increase access of orphans and vulnerable children including Almajiri child to basic education and other services in Bauchi and Sokoto, through innovative approaches such as learning centers that will cater to the literacy needs of out-of-school youth and mainstream them into the formal education system.

Almajiri children are integrated into this approach to address their special vulnerability. Services include inschool and out-of-school activities, life skills education, and psycho-social support skills building for teachers and community members. The children will also be provided with referrals to health centers in their locality that are supported by additional USAID health and HIV interventions.

In each of the Almajiri learning center NEI provided the following facilities and services:

- Provision of daily meal (breakfast)

- Teaching of literacy and numeracy

- Payment of facilitators, craft men, women \& proprietors monthly allowances.

- Provision of basic cleaning materials

- Provision teaching aids

- Formation of center base management committee (CBMCs)

- Provisions of Vocational training equipments

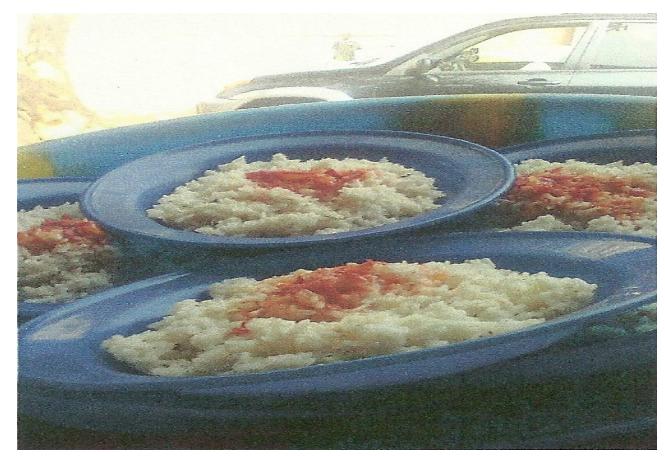

daily feeding of almajirai in one of the center

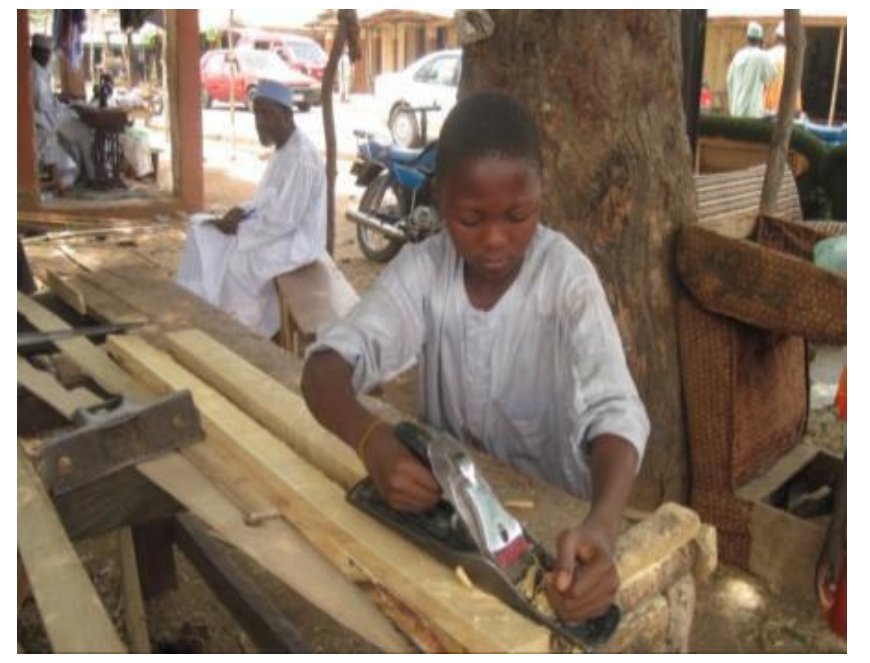

Literacy and numeracy class in sessio

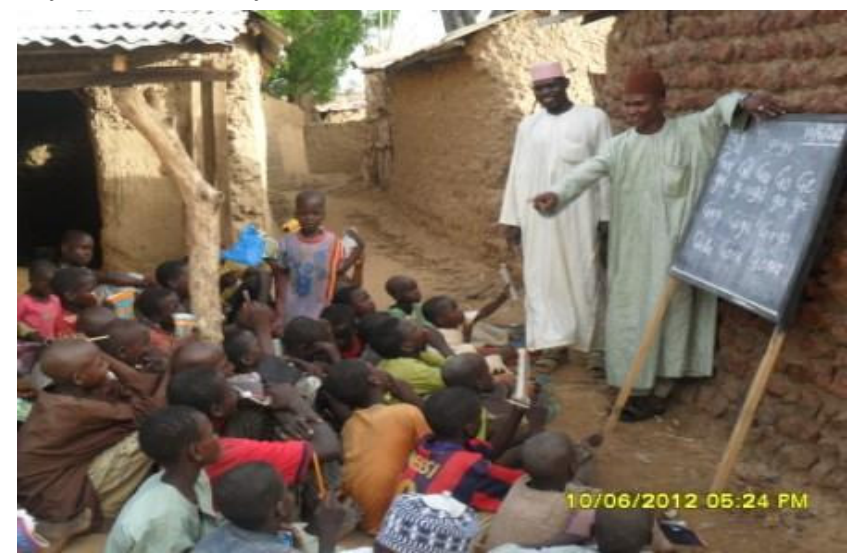

One of the apprentice center in Sokoto state

a vocational training in one of the Almajiri center
Strengthened state and local government capacity to deliver basic education services by addressing key issues in the management, sustainability, and oversight of basic education in Sokoto and Bauchi. Systems strengthened include:

Policy development and implementation

- Information management and data for decision-making Human

resource

○

development and management, including training, monitoring, and supervision

Financial resource management and budgeting - Increased access to primary education, particularly for girls - Increased access of orphans education and support, including:

o In school and out of school activities

Life skills education In the area of Almajiri integrated programme the following are achieved: 


\begin{tabular}{|c|c|c|c|c|c|c|c|c|c|}
\hline \multicolumn{2}{|c|}{$\begin{array}{l}\text { Basic } \\
\text { Literacy }\end{array}$} & \multicolumn{2}{|c|}{$\begin{array}{l}\text { Vocational } \\
\text { Skills }\end{array}$} & \multicolumn{2}{|c|}{ Apprenticeship } & \multicolumn{2}{|c|}{$\begin{array}{l}\text { Mainstreamed to } \\
\text { Formal School } \\
\text { system }\end{array}$} & \multicolumn{2}{|c|}{$\begin{array}{l}\text { Post } \\
\text { literacy }\end{array}$} \\
\hline M & F & $\mathrm{M}$ & $\mathrm{F}$ & $\mathrm{M}$ & $\mathrm{F}$ & $\mathrm{M}$ & $\mathrm{F}$ & $\mathrm{M}$ & $\mathrm{F}$ \\
\hline 367 & 217 & 543 & 461 & 940 & 668 & 367 & 217 & 210 & 101 \\
\hline 587 & & 100 & & 160 & & 587 & & 311 & \\
\hline
\end{tabular}

\section{Northern Education Initiative plus (NEI-plus/USAID funded Project)}

More than 30 percent of school-aged children in Northern Nigeria do not have access to basic education. This is attributed to a combination of factors, including cultural attitudes, lack of educational facilities and insecurity as a result of the insurgency. The quality of education is also much to be desired. Factors contributing to this include: Inadequate teacher preparedness and low motivation; lack of quality teaching and learning materials; insufficient funding to education; and inadequate parental and community support

To address these challenges, the Nigeria Northern Education Initiative Plus (NEI+) program seeks to improve access and quality of education for more than 2 million school-aged children and youth in two northern states. Funded by the U.S. Agency for International Development, the five-year program will strengthen the states' ability to provide quality education - especially for girls, orphans and children enrolled in nontraditional schools - and improve children's reading skills. NEI-plus have been implementing in Bauchi and Sokoto state

\section{NEI-plus Project Graduated 188,950 out-of-school-children that acquire Basic Literacy at the Non-} Formal Education Centers in Nigeria.

More than 188,950 out-of-school children have learnt basic literacy and numeracy to further their education

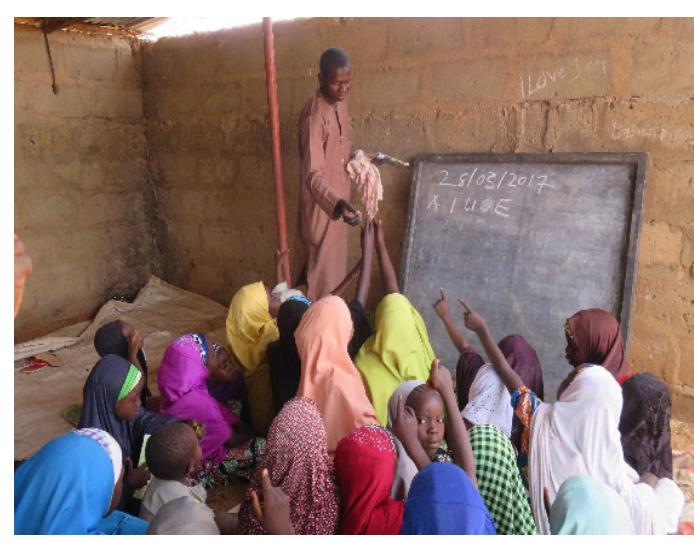

The NEI-plus effort as development partner between the year 2016 to 2018 graduated 188,950 out of school children and youths to respond to the increase demand from the Government and communities in the targeted LGAs to enroll more out of school children to access basic education most of these kids are found in Almajiri Qur'anic schools across the Northern part of the country. In year 4 quarter one has recorded implementation of community mapping to determine location of the more out of school children. CSOs and Access and fragility coordinators were trained as data collectors. Community mapping data was collated, entered, analyzed and disseminated. The mapping exercise facilitated the identification of more out of school. Mapping report guided the cohort 4 activities. The initiative planned to stablish 990 NFLCs in cohort 4. The 990 NFLCs will include 15\% Adolescent girl learning centers and $15 \%$ Youth learning centers.

The CSO guided by community mapping report are currently establishing the NFLCs, hiring of learning facilitators, program officers and enrollment of learners. The Sokoto cohort 4 activities was planned by CSOs with guide from the Access coordinators with coordination form the AFO.. The cohort 4 activities plan support the Access team to track CSO cohort 4 activities implementation within the time frame. It was agreed that identification of centers, advocacy activities, establishment of the 990 NFLCs, hiring of the learning facilitators, enrollment of learners should be completed in December 2018.

The distribution of the TLM to LGA store by the state TLM distribution committee was planned to conduct on 14-15 Jan 2019. Until recently, Hadiza Hamza was one amongst millions of children not attending school in Northern Nigeria. Leaving in Malamawa community of Sokoto state with limited access to formal education, Hamza and her six siblings attended Qur'anic studies and helped their parents during the farming seasons.

Now she sits at the back of a classroom in fourth grade at Malamawa Primary School pointing at words in a passage and reading aloud with other pupils. Last year, Hamza enrolled for a basic literacy program in community-based non-formal learning centers introduced by USAID's Northern Education Initiative Plus.

USAID's Northern Education Initiative Plus is providing access to quality education and improves reading skills for more than two million school-aged children in formal and nontraditional schools. 
Through the project thus far, about 36,000 children who were out-of-school were enrolled in 800 learning centers spread across educationally disadvantaged communities in Bauchi and Sokoto states. The project targeted children between ages 5-17 years, training educated community members as learning facilitators to teach literacy, numeracy and life skills in the Hausa language.

During the six-month program, children like Hamza attended classes for a minimum of six hours every week and received textbooks developed by the project and other writing materials to aid their learning.

When a center opened in her community, Hamza asked her father, who is an Islamic Cleric, to enroll her. "I enjoyed attending classes. I loved my books. I liked the pictures especially the airplane. I know one day I will travel in it when I become a teacher," she said.

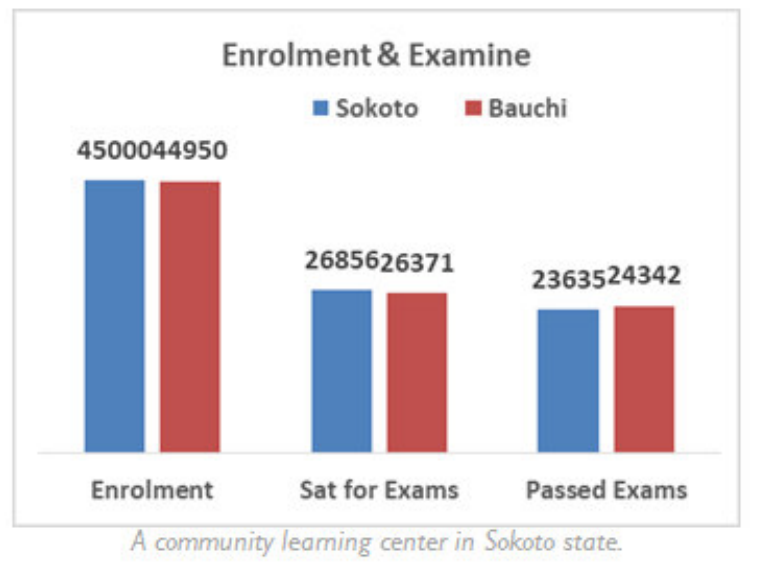

Hamza is making progress towards that dream.

In March 2017, she wrote and passed an exit

examination certifying she had completed the

basic literacy program and also providing the

opportunity to further her studies in fourth

grade at a formal school.

This exam was conducted by the regulatory

body for non-formal education in Bauchi and
Sokoto states, the State Agency tor Mass

Education. More than 80 percent of 31,631

children tested on literacy, numeracy and life

skills subjects taught during the basic literacy

program passed and qualified to be

mainstreamed into formal school

\section{Federation of Muslim Women Association of Nigeria (FOMWAN)}

FOMWAN as a part of Civil Society have been providing various supports and services nationwide. With coming of NEI and NEI-plus project FOMWAN serve as partner by complementing all the components efforts toward achieving the project goal and objectives. Through advocacy visits, sensitizations, trainings and management of Non-formal learning centers, Kid forums, Adolescents Girls Program (AGPs) and Community Collation (CCs). FOMWAN contributed to the achievement of the project objective, by participating in the development of Medium Term Medium Term Sector Strategy (MTSS) and State Teacher Education policy in collaboration with CSACEFA, Education Planning and Management (EPM) and Teacher Education (TE).

FOMWAM also sensitized 30(18f-12m) CBOs/ FBOs on MTSS /STEP and solicited their support to advocate for the adaptation and implementation of the documents in the states and conducted 7 high level advocacies with members from the 2 policy champion committees in Bauchi and Sokoto. Sensitized Two hundred and fifty (240) female SBMC members on the importance of active participation in school decision making in 120 NEI Schools. 220 Religious leaders were sensitized to prioritized basic education needs of their LGA for inclusion in the Local Government Education forums in 20 pilot LGAs. We also conducted one day dissemination/sensitization meeting with 98 (56m-42f) Government/SCOs participants on the developed guidelines for Freedom of Information Act; Formed Coalition of NGOs for FOIA and conducted advocacies that led to easy access to information at SUBEB level; Obtained 50 copies of the Freedom of Information Act. and distributed to CSOs and government partners.

Conducted progress review meeting with $30(20 \mathrm{~m}-10 \mathrm{f})$ policy champions and TWG members and came up with joint high level follow up advocacy plan on the implementation of STEP and MTSS in Bauchi and Sokoto; conducted high level advocacy to State House of Assembly Education Committee, MOE, SSCOE and SUBEB, that led to the House to invite relevant officer for discussion and signing the documents into law. FOMWAN trained 122 ( $25 \mathrm{f} 95 \mathrm{~m}$ ) SBMC members 10 from each of the formal school in Shagari and Alkaleri LGAs on the revised/ Hausa version of WSDP manual (to include WASH and DSS). FOMWAN monitored the implementation of 20 LICs CEF activities in 20 pilot LGAs in Sokoto. Under FOMWAN has contributed to almost all the indicators by serving as Sub-grantee and partner as follows 
- $\quad$ FOMWAN paid advocacy visits to 20 LGA chairmen and their council members and 40 traditional leaders to leverage resources for OVC. FOMWAN has also sensitized more than 15,000 women on OVC issues and available NEI Non formal learning centers in the 2 pilot States. In addition, 60 traditional/religious leaders and 60 key members have also been sensitized on NEI goal and objectives and vocational skills available in the non formal learning centers. We have also identified and oriented 20 master craftsmen on the project goal and expectations and assessed 16 non formal learning centre's available vocational skills program in the 2 pilot LGA. Also, 48 OST members have been nominated and trained on how to use CSI tool to identify OVC, they in turn selected and registered 640 OVC in 16 NFLCs. Built capacities of 38 FOMWAN members on communication skills and information dissemination.

- FOMWAN conducted advocacies to CCs on appropriate care and support for OVCs. Additionally, FOMWAN conducted monitoring visits to keep track of the educational progress of registered OVCs. In collaboration with CSACEFA, FOMWAN conducted advocacies to education secretaries to request for posting of more permanent facilitators to the NEI NFLCs as a key step in ensuring sustainability, effective teaching and learning as well as ensure adequate number of learners per teacher. FOMWAN also orientated 20 members of LGA branches and five affiliate organizations on the need to open and manage non-formal learning centers in their communities.

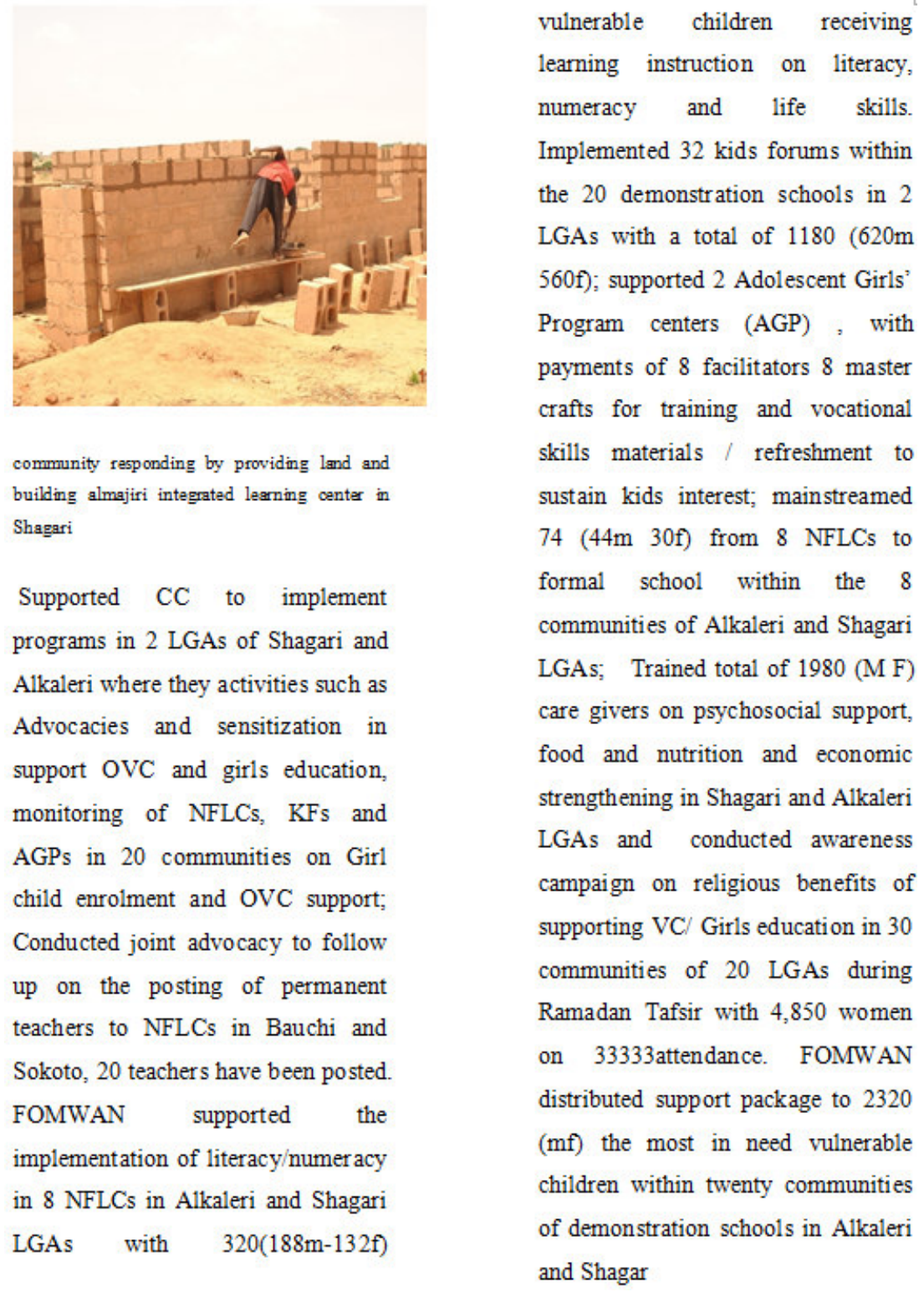

- FOMWAN collaborated with CC and sensitize (120m) household and they supported 66(males) OVC with dinner, in 4 districts of Shagari and Alkaleri LGAs. 360 womens' awareness was increased on the benefits of girl's education and the available vocational skills in the LGAs. FOMWAN Linked 146 
(M78-F68) OVC with master crafts-men/women for apprenticeship on different trades of their choice. Distributed support packages to over 1000 VCs in Shagari and Alkaleri LGAs.

\section{Civil Society Action Coalition on Education for All (CSACEFA)}

CSACEFA is established as a pressure group in the area of education and is committed to the attainment of EFA goals which are:

- Expanding and improving comprehensive early childhood care and education, especially for the most vulnerable and disadvantaged children

- Ensuring that by 2015 all children, particularly girls', children in difficult circumstances and those belonging to ethnic minorities have access to and complete free and compulsory primary education of good quality.

- Ensuring that the learning needs of all young people and adults are met through equitable access to appropriate learning and life -skills programmes.

- Achieving a 50 percent improvement in levels of adult literacy by 2015 , especially for women, and equitable access to basic and continuing education for all adults.

- Eliminating gender disparities in primary and secondary education by 2005 and achieving gender equality in education by 2015 , with a focus on ensuring girls' full and equal access to and achievement in basic education of good quality.

- Improving all aspects of the quality of education and ensuring excellence of all, so that recognized and measurable learning outcomes are achieved by all, especially in literacy, numeracy and essential life-skills.

\section{Contribution of CSACEFA in partnership with NEI 2010-2019}

All NEI Work plans was actively participated by CSACEFA, Ministries, Boards, Agencies and nongovernmental organizations NGOs in Bauchi and Sokoto States. CSACEFA as National partner and a subgrantee on the project participated actively in the selection of 10 pilot LGAs based on the state driven selection criteria, 100 demonstration schools made up of 40 public schools, 20 Islammiya schools and 20 OVC learning centers) CSACEFA in Collaboration with NEI established structures in the LGA, 10 Community Coalition CCs, 10 orphan support team (OST). Established 2 Adolescent program where girls are thought basic literacy, numeracy life skill and vocational skill this program is put together for girls that drop out of school due to one reason of the others or Girls that have never attended formal school the within the ages of 12 to 17 years. CSACEFA Collaborated with Education Planning and Management to establish Community Education forum (CEF) in Sokoto. Conduct five days Orientation training for CSACEFA desk officers, LGEA planning officers, CSACEFA members and NEI staff on budget tracking, advocacy and campaign skills. Conduct Capacity building on school report card questionnaire, survey and advocacy skills for CCs, SBMCs and CSOs. CSACEFA conducted a rapid assessment of interventions by different stakeholders to SBMC $\mathrm{s}$ in demonstration schools. CSACEFA held meeting with 180 SBMCs from the 10 pilot LGA to ascertain the process of decision making and feedback mechanism at school/ community level. Two days meeting was held with $40 \mathrm{CCs}$ to share findings of formative research and strategies to effectively implement adolescent girls program (AGP). CSACEFA Conducted a Radio discussion program on Rima Radio Sokoto on factors affecting adolescent girl's school retention and completion in collaboration with FOMWAN and Ministry of women affair. CSACEFA collaborated with other NEI component in order to achieve the overall goal of NEI

\section{Advocacies to Stake-holder in Sokoto State}

CSACEFA under took some activities aimed at contributing to NEI two objectives. This include advocacy visits to State Universal Basic Education Board (SUBEB) chairman, State House of Assembly, Nigeria Union of Teachers (NUT), Ministry of Women Affairs to solicit support for the approval of State Teacher Education Policy (STEP) into Law. CSACEFA collaborated with the Teacher Education component of NEI and state partners to adapt the National Teacher Education Policy (NTEP) to State Teacher Education Policy (STEP) incorporating state peculiarities for each of Bauchi and Sokoto states. CSACEFA conducted advocacy visits for adoption and implementation at the state level, worked with the Basic Education Technical Working Group (BETWG) and Steering Committee (SC) in each state to examine teacher related issues, develop Teacher Recruitment and Deployment (TRD) guidelines for each state to streamline its recruitment and deployment procedures and institute a Quality Assurance strategy for effective monitoring and supervision of teachers statewide. 


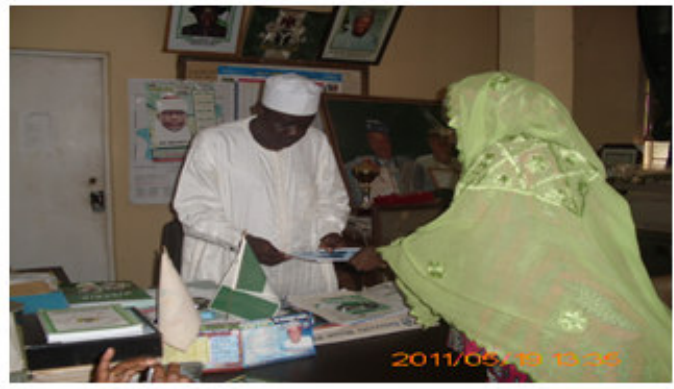

Submitting advocacy documents to Chairman SUBEB Soloto

\section{Policy Integrations}

CSACEFA identified 20 prominent stakeholders in the states who are referred to as policy champions) the chairperson of policy champion in Sokoto state is the former commissioner of education Dr. Kulu Haruna Abubakar CSACEFA developed advocacy kit for the policy champions, policy champions identify issues in education with a view of finding lasting solutions to them. They were especially useful in mediating with SUBEB to end up teacher strike in Bauchi Three days Step down training was organized by CSACEFA on Whole School Development Plan (WSDP) for SBMC members in twelve schools (12) NEI demonstration schools In Sokoto state respectively, where 240 SBMCs were trained in Bauchi and Sokoto $(96 \mathrm{~m}, \mathrm{f} 24)$ Community coalitions ( $\mathrm{CCs}$ ) Bodinga were supported with fund to carry out their action plan.

CSACEFA conducted meeting in collaboration with and EPM to disseminate and sensitize government and CSOs stakeholders on the developed guidelines on freedom of information act. This is contributing to Result

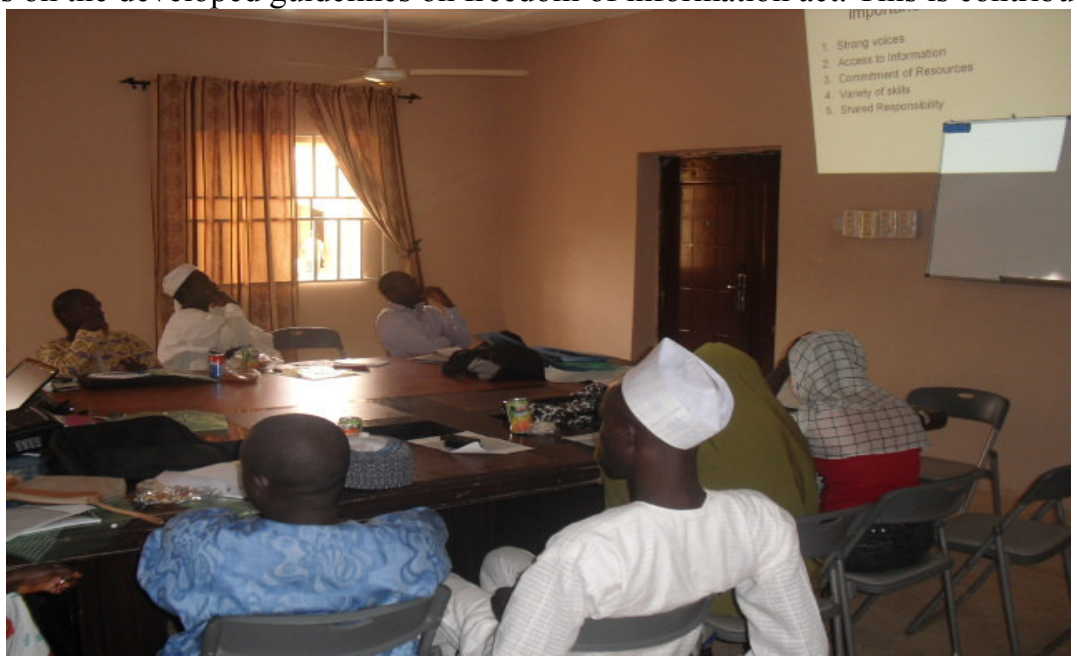

CSOs and government partners held one day meeting on guideline for freedom of information act

\section{Monitoring and Project Sustainability}

The monitoring was done to ensure compliance by mentor teachers in delivering the content of the training manual and also to monitor the attendance of teachers from NEI demonstration schools. CSACEFA this year has enrolled 50 adolescent girls to acquire basic literacy, numeracy and vocational skills. Continues supporting the implementation of kids forum activities in (29) centers in Dass and Bodinga LGA

To continue to support to Almajirai integrated education CSACEFA focus on activities that will be sustainable in the communities, they conducted palace based mobilization for leveraging resources among the communities' members to continue to sustain NEI and NEI-plus activities in the communities plan. 


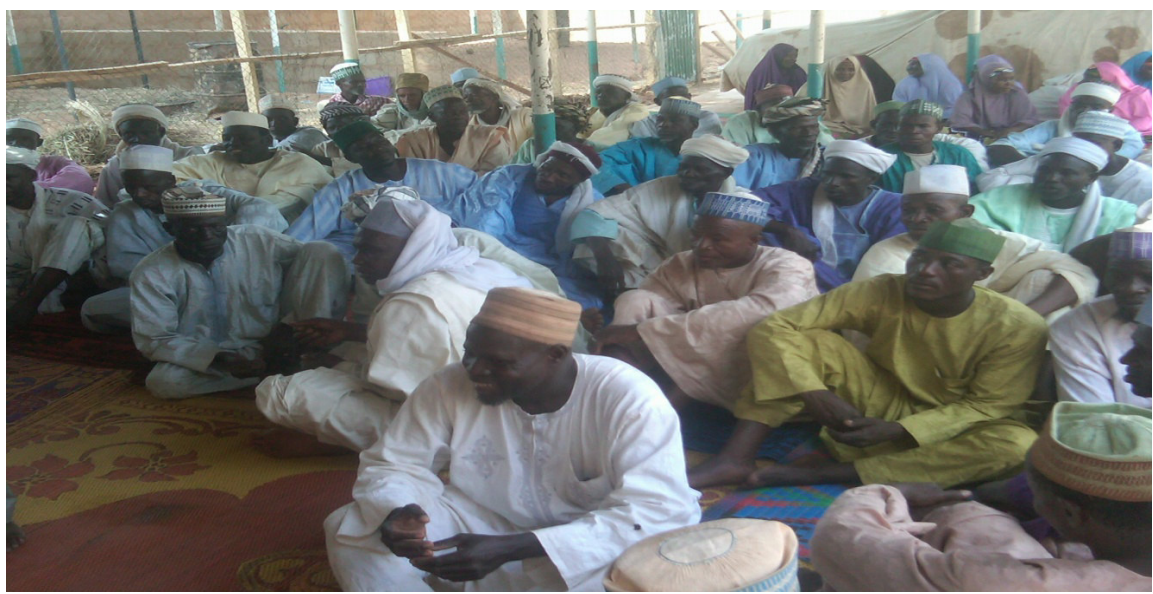

CSACEFA conducted palace-based mobilization to leverage resources \& support for OVC

CSACEFA Participated in Training of Trainers (ToT) of caregivers organized by OVC WA. In year 2-4 CSACEFA Conducted training for 1,976 caregivers of OVC on House Hold Economic strengthening this activity is linked to Sub result 2.2.4: Capacity of Communities and Caregivers to support OVC education and well being built.

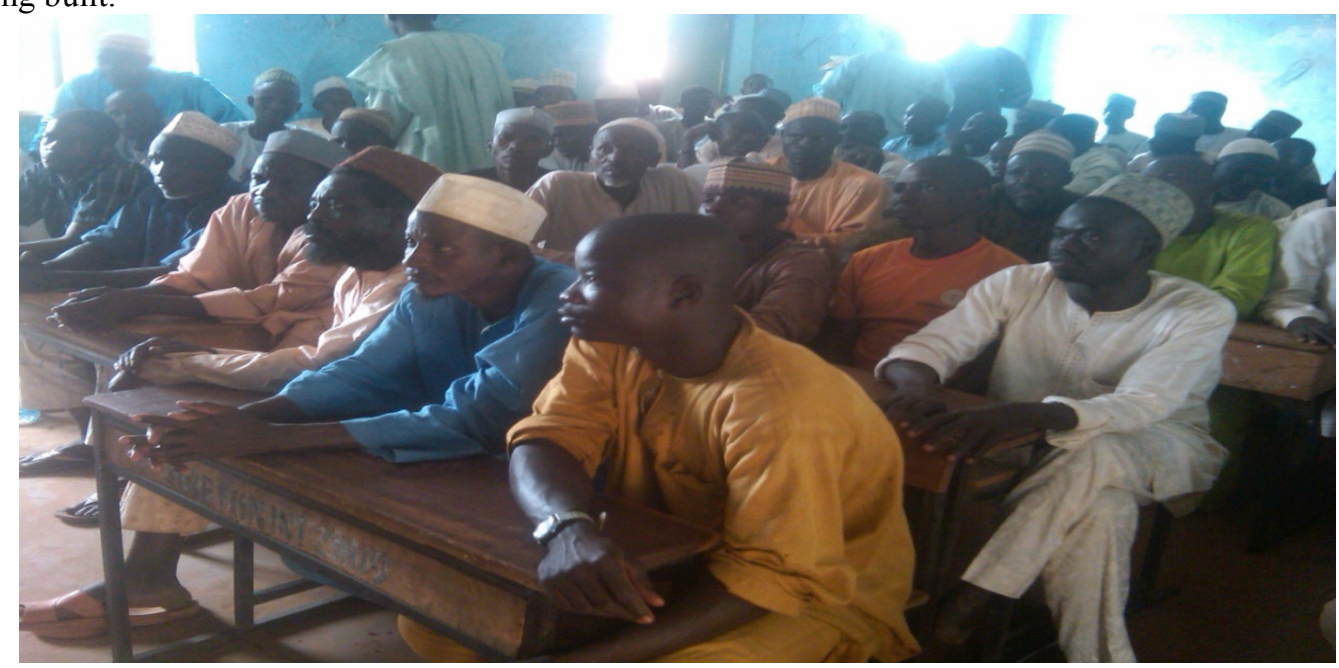

CROSS SECTION OF CAREGIVERS RECEIVING TRAINING ON HH ECONOMIC STREGTHENING

As part of CSACEFA sub-grant activities was establishing and managing Almajiri integrated Centers which are called Non-formal Learning Centers in 4 areas of Bodinga local

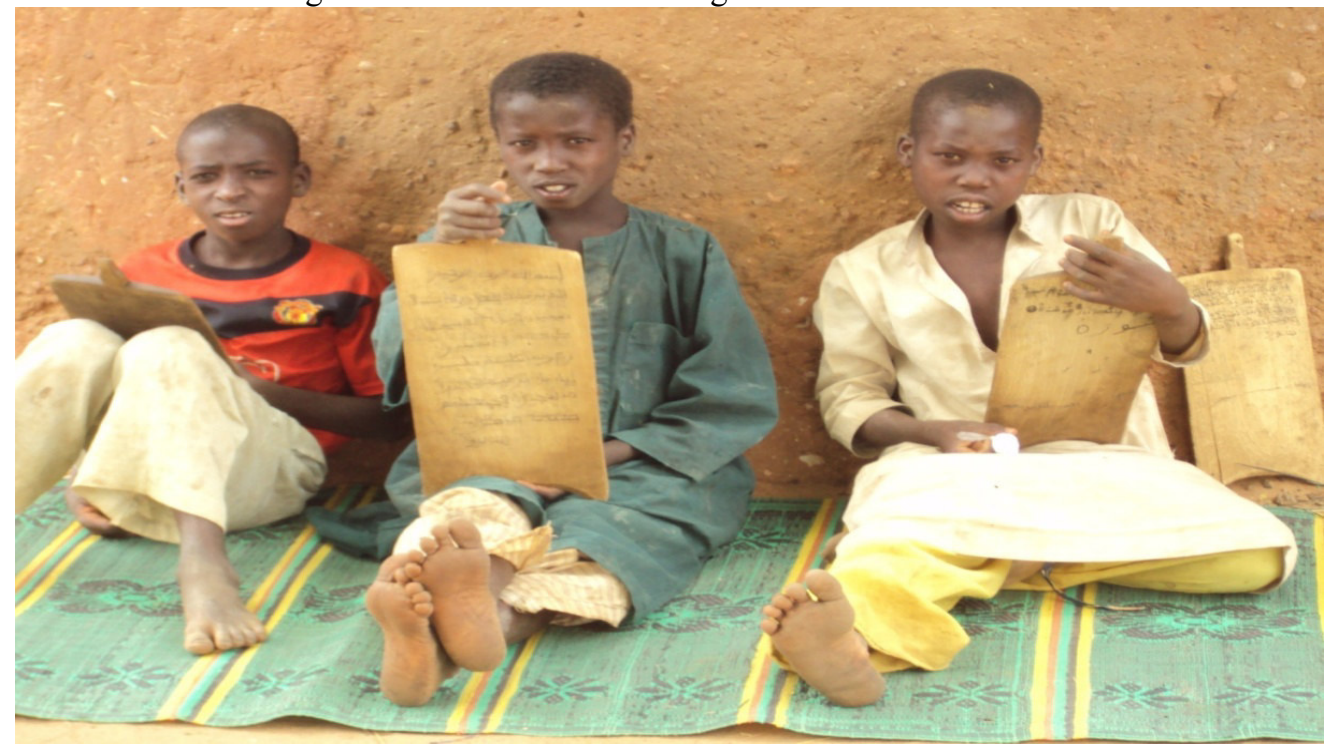

These 3 leaners are now in Formal primary schools in Boginga and Sifawa town 


\section{Conclusion}

The best practices are the key word to Development Partners in the implementation of any social services they embark upon, that occurred because they normally addressed System and ensure transparency and dedication to implementations of projects. However, to optimally gain a sustainable benefit of these interventions the Development Partners may require these thoughts; The absence of a distinct and comprehensive framework for Government /Bilateral/Multilateral and NGO collaboration leaves a serious problem for partners wanting to work through other agencies. Ministry of Education for instance must persuade all partners to sign a Joint Implementation Memorandum involving Government, donors, local NGOs and international NGOs. This agreement should also take account of reporting and accountability requirements to enhance protection and transparency.

The Almajiri integrate Education now have weak co-ordination of development partner activities continues to be a serious issue. The inability of donors to agree on common participatory processes puts developing countries with limited logistics for project formulation under undue stress resulting in the impression that country programs are more donor driven than is actually the case.

The Government partners has to provide strategic leadership in this regard by agreeing to use the logical framework approach as an entry point to strategic thinking. In spite of this all donors alike developed their specific focus and orientation based on their internal requirements resulting in slippage in the original implementation schedules. Indeed as a result of this practice the donors could not endorse the common basket approach to financing the basic education program.

Strategically the institutional difficulties of buying into a Nigerian program have become more apparent as various sub elements are in danger of being further fragmented due to the fact that donors have

\section{Reference}

Millett, C. M., Stickler, L. M., Payne, D. G., \& Dwyer, C. A. (2007). A culture of evidence:

Critical features of assessments for postsecondary student learning. Princeton, NJ:

Educational Testing Service. Retrieved August 22, 2008, from http://www.ets.org/Media/Resources For/Higher_Education/pdf/4418 COEII.pdf

Tahir G. (2006) Speech of the Executive Secretary, Universal Basic Education Commission at a One-Day Stakeholders Meeting on the Integration of Qur'anic Education into the UBE Programme, held at Hamdala Hotel, Kadfuna, on $28^{\text {th }}$ June, 2006.

United Nations Educational Scientific and Cultural Organization (2006). Literacy for Life. Education for All Global Monitoring Report. Paris: UNESCO.

UNESCO Institute for Lifelong Learning, (2011). The state and development of adult learning and education in Sub-Saharan Africa Regional Synthesis Report. In John Aitchison and Hassana Alidou (eds). Germany, Author.

US Department of Labour, (2010) in Sherma, R,. Tibbetts, J., Woodruff D., \& Weidler, D. (2010). Instructor Competencies and Performance Indicators for the Improvement of Adult Education Programmes. A Publication of PRO-NET

US Department of Education, (2012) in Sherma, R,. Tibbetts, J., Woodruff D., \& Weidler, D. (1999).

Instructor Competencies and Performance Indicators for the Improvement of Adult

Education Programmes. A Publication of PRO-NET. 